\title{
Congenital chylothorax
}

INSERM

\section{Source}

INSERM. (1999). Orphanet: an online rare disease and orphan drug data base. Congenital chylothorax. ORPHA:264688

Congenital chylothorax is a rare, potentially life-threatening neonatal condition characterized by the accumulation of chyle within the pleural space leading to respiratory distress, malnutrition and immunological compromise, either immediately after birth or within the first few weeks of life. Congenital chylothorax is the most common cause of pleural effusion in neonates; it can occur primarily due to developmental anomalies of the lymphatic duct or can be associated with chromosomal anomalies (e.g. Noonan syndrome, T urner syndrome and Down syndrome), hydrops fetalis, mediastinal neuroblastoma and other cong enital malformations. 